\title{
Incorporating Land Cover within Bayesian Journey-to-crime Estimation Models
}

\author{
Joshua D. Kent ${ }^{1} \&$ Michael Leitner ${ }^{2}$ \\ ${ }^{1}$ Center for GeoInformatics, Louisiana State University, Baton Rouge, Louisiana, USA \\ ${ }^{2}$ Department of Geography \& Anthropology, Louisiana State University, Baton Rouge, Louisiana, USA \\ Correspondence: Michael Leitner, Department of Geography \& Anthropology, Louisiana State University, Baton \\ Rouge, Louisiana, 70803, USA. Tel: 1-225-578-2963. E-mail: mleitne@lsu.edu
}

$\begin{array}{lr}\text { Received: March 31, } 2012 & \text { Accepted: April 11, } 2012 \quad \text { Published: June 1, } 2012 \\ \text { doi:10.5539/ijps.v4n2p120 } & \text { URL: http://dx.doi.org/10.5539/ijps.v4n2p120 }\end{array}$

\begin{abstract}
Crime occurs within asymmetrical landscapes that are occupied by physical and cultural structures that influence a criminal's behavior in space. These structures manipulate the distribution of available targets and bias the offender's perceptions of opportunity and target attractiveness. A recent study demonstrated that criminal geographic profiles can be enhanced to accommodate such ecological characteristics by using land cover classifications as a proxy for these structures. This study expands on these earlier findings by incorporating land cover classes within a Bayesian probability framework. Seven traditional and land cover enhanced geographic profile models for fifty-two burglary, robbery, and larceny serial offenses were compared. Overall, land cover enhanced models performed significantly better than non-enhanced techniques for measures of search costs andprobability estimation. Tests measuring a profile's error distance were mixed and failed to confirm significance between paired comparisons.
\end{abstract}

Keywords: serial crime, environmental criminology, geographic profiling, landscape

\section{Introducation}

The unknown serial offender initiates criminal activity from a residence, or anchor point, located within an anisotropic plane. That is, the relationship between offender, target, and criminal opportunity does not exist as a collection of random events distributed across space (Brantingham \& Brantingham, 1981; Capone \& Nichols, 1975; 1976). Rather, these dimensions of crime are governed by physical and cultural structures that are unique to the environment in which they occur (Brantingham \& Brantingham, 1981). Yet, contemporary techniques for modeling a criminal's spatial behavior will typically adopt the a priori assumption that opportunity and target access reside on an isotropic surface surrounding the offender's anchor point (i.e., that location from which the serial offender will consistently initiate his or her crimes). Because these techniques are incapable of accounting for inherently asymmetrical landscapes, modeled output becomes susceptible to errors that can result in the overor under-estimations of the offender's behavior in space, thus failing to predict the criminal's actual point of origin (Kent \& Leitner, 2009; Rengert, Piquero \& Jones, 1999). By focusing on those factors that reflect the implicit variability imposed by the environment, it may be possible to more consistently identify the criminal anchor point and provide an enhanced investigative strategy for apprehending the serial offender.

Previous research by Kent and Leitner (2009) demonstrated that the social and environmental constraints influencing the criminal activity space [i.e., the finite area defined by the event nodes and paths utilized by the offender (Brantingham \& Brantingham, 1981)] can be parameterized within a crime model using land cover characteristics. When applied as a filtering mechanism, the land cover type associated with the residences of known serial offenders was found to be an effective approach for generating accurate and precise estimates of the unknown criminal's anchor point. But, to what extent can land cover be used to enhance a geographical profile of an offender's behavior in space if it were directly integrated within contemporary modeling techniques? This research will examine this question and expand on previous findings to assess the efficacy of incorporating land cover probabilities within a Bayesian framework. To test this hypothesis, traditional and land cover-enhanced models will be used to create geographic profiles for a random sample of solved serial crimes that occurred in Baltimore, Maryland between 1993 and 1997. Results derived from each profile will be compared and assessed for accuracy and precision. This study will conclude with a discussion of findings and 
recommendations for continued research.

\section{Background}

Geographic profiling is an investigative technique used to reveal the most likely location of the offender's anchor point (typically a domicile) by analyzing the geographic locations of a connected series of crimes. Law enforcement agencies primarily use it as a decision support tool from which to develop investigative strategies. This is typically accomplished by prioritizing a suspect list from sex offender registries, identifying likely informants, and linking crime characteristics to known modus operandi. Profiles may also be used to generate an area prioritization map from which law enforcement personnel can better position surveillance, assign neighborhood canvassing, and modify patrol deployments (Rossmo, 2000). Criminologists and researchers also use geographic profiling to enhance the broader understanding of a criminal's spatial behavior, i.e., the overriding laws that characterize criminal mobility patterns (Brantingham \& Brantingham, 1981; Rengert et al., 1999). Such efforts establish the technological and theoretical innovations that are often embraced by practitioners. At the heart of contemporary geographic profiling techniques are theoretical tenants that characterize the ecological nature of criminal behavior in space.

\subsection{The Ecology of Crime}

Indeed, the utility of a geographic profile is realized through its ability to formulate inferences and reveal characteristics about an offender's spatial behavior. This approach originates from concepts derived from environmental criminology (Brantingham \& Brantingham, 1981). Four theories that characterize the ecological relationships between criminal behavior and place are (1) routine activity theory (Cohen \& Felson, 1979; Felson \& Clarke, 1998), (2) rational choice theory (Cornish \& Clarke, 1986), (3) crime pattern theory (Brantingham \& Brantingham, 1981), and (4) the principle of environmental range (Canter \& Larkin, 1993). Comprehensively, these concepts establish that an offender's behavior in space is the product of rational decision making from which the perceptions of criminal opportunity and target attractiveness are constrained by the physical and cultural environments in which they exist (Brantingham \& Brantingham, 1981; Canter \& Larkin, 1993; Cohen \& Felson, 1979; Rengert et al., 1999; Rhodes \& Conly, 1981).

\subsection{Contemporary Geographic Profiling Models}

As demonstrated in earlier studies, an offender's geographic behavior will exhibit deliberate biases that coincide with the tenets of environmental criminology (Brantingham \& Brantingham, 1981; Canter \& Larkin, 1993; Capone \& Nichols, 1975; 1976; LeBeau, 1987; Leitner, Kent, Oldfield, \& Swoope, 2007; Kocsis \& Irwin, 1997). Consequently, spatial patterns emerging from such behavior can be modeled with varying degrees of success. Nearly all contemporary criminal investigations apply some method for geographically profiling an offender's behavior in space. Most of these techniques apply quantitative models that are based on fundamental geographical principles. Spatial distribution and spatial interaction models dominate contemporary geographic profiling methods. The spatial distribution approach includes measures of central tendency (e.g., geographic mean, median, and center of minimum distance) and diffusion (e.g., areal circle, standard deviational ellipse, and convex hull). These simple techniques have demonstrated notable effectiveness as fast, intuitive, and cost-effective investigative tools because they capitalize on spatial behaviors characterized by the principle of least effort (Levine, 2005; Paulsen, 2006a; 2006b; Snook et al., 2004; 2005; Leitner et al., 2007). Furthermore, centrographic methods are often presented as diagnostic routines that provide benchmarks for assessing the performance of multiple methods (Bernasco \& Block, 2009; Paulsen, 2006a; Levine, 2009). However, single descriptive measures such as these are susceptible to outliers, and are thus often criticized for their inability to provide an efficient search strategy for locating an anchor point (Levine, 2005; Snook et al., 2005; Taylor, Bennell, \& Snook, 2009).

The second approach typically involves sophisticated spatial interaction models that assess the criminal commute. Specifically, these models characterize the criminal's distance decay: spatial behavior in which the frequency of criminal activity decreases as the distance from the anchor point increases. The majority of contemporary models characterize the distance decay effect as it relates to the costs and benefits of committing a criminal offense (Brantingham \& Brantingham, 1981; Capone \& Nichols, 1976; Cohen \& Felson, 1979; Lottier, 1938; Turner, 1969). Perhaps the most common method for modeling distance decay is the Journey-to-Crime (JTC) estimation. JTC estimates produce maps representing the most likely location of a serial offender's anchor point based on the travel patterns observed for previously solved serial crimes. Accordingly, these techniques are able to reveal portions of the unknown offender's activity space, as well as providing investigators with a usable search strategy for locating the anchor point. The techniques for this approach are well documented and will not be discussed here (Levine, 2007; Rossmo, 2000). Despite the popularity, JTC estimation models are often 
criticized for theoretical and empirical limitations (van Koppen \& de Keijser, 1997; Rengert et al., 1999; Snook et al., 2005; Smith, Bond, \& Townsley, 2009). To overcome these caveats, many researchers have pursued, with notable success, alternative heuristics for profiling offender behavior in space (Paulsen, 2006a; Snook, Canter, \& Bennell, 2002; Snook et al., 2005; Taylor, Bennell \& Snook, 2009). However, these techniques continue to omit the environmental factors associated with criminal opportunity and target attractiveness. Another approach, based on Bayesian probability theory, appears well-suited to account for the fundamental tenets of environmental criminology.

\subsection{The Empirical Bayesian Paradigm}

Bayesian probability represents an intuitive process for quantifying the degree of belief in a hypothesis before and after evidence has been observed. In many respects, the Bayesian approach follows the same process as the scientific method. As evidence is accumulated, the hypothesis adjusts according to how likely that new evidence would be observed under any condition. Because the Bayesian approach quantifies the degree to which new evidence can modify the hypothesis, it has increasingly become an attractive paradigm for decision support processes.

A Bayesian formulation for modeling a serial offender's spatial behavior was first operationalized by Levine (2007). The methodological advantage of the Bayesian formulation is that it is capable of incorporating the principles of environmental criminology as conditional factors associated with the distance decay models used in JTC estimates. It does so by statistically relating the crimes committed by an unknown offender with the crimes committed by a calibration sample of known offenders. By joining the elements from solved cases with those of the unsolved, criminal opportunity and target attractiveness become implicit factors that are represented by calculating (a) the likelihood of an anchor point derived from known offenders that committed crimes the same location as the unknown offender; and (b) the marginal probability of all known anchor points located in the study area.

The ability to account for offender perception and mobility characteristics notwithstanding, the Bayesian JTC framework suffers from two fundamental limitations. First, the product of the JTC prior and conditional likelihood functions is vulnerable to over- and under- estimation errors that can mislead an investigation. For instance, this estimate can only emphasize, at the exclusion of all others, those locations immediately surrounding the anchor points of previous offenders. In short, the technique favors those anchor point locations where offenders tend to cluster. This is especially problematic if the unknown offender initiated crimes from locations that are not consistent with those observed in solved cases. Consequently, these outlier anchor points will be assigned a low probability estimate, thus diminishing the investigative value of the profile. The second limitation of the Bayesian and indeed all JTC approaches relates to their inability to exclude those locations that are a priori unlikely to contain an anchor point (e.g., rivers, lakes, deserts, mountain tops, or other unlikely environment). Many profiling applications retain these locations within the modeled output (e.g., Canter et al., 2000; Levine, 2007; Rossmo, 2000). Such locations impose a bias on the estimates; thus reducing the accuracy and skewing the precision of the results. To overcome all these limitations, environmental characteristics that define the offender's activity space should be formally incorporated within this modeling framework (Brantingham \& Brantingham, 1981; Capone \& Nichols, 1976; Rengert et al., 1999; Rhodes \&Conly, 1981). Doing so ensures that the profiled estimates can better account for those environments that are more likely to contain the offender's anchor point.

\subsection{Incorporating Land Cover}

Kent and Leitner (2009) demonstrated that land cover characteristics can be used as a proxy for the physical and cultural features that define the offender's activity space. The authors compared the performance of traditional and Bayesian JTC models against land cover enhanced models. Land cover techniques produced JTC estimates that essentially filtered from the modeled output those areas which were unlikely to contain the anchor point. Their results revealed significant, but sometimes mixed, performance gains. Their technique effectively validated the premise that a deterministic relationship exists between land cover characteristics, crime scene distribution, and the location of an offender's anchor points. However, these estimates suffered from biases similar to those cautioned in the preceding discussion. Despite producing effective geographic profiles, the technique was vulnerable to a "rotten apple" effect: A so-called condition in which the maximum likelihood estimate for the land cover parameter failed to adequately represent the true anchor point. Under these circumstances, geographic profiles either underperformed or failed whenever the unknown offender initiated crimes from a land cover type that was unlike those observed in the calibration sample. To resolve this problem, the technique must be redefined to take on a Bayesian formulation. The advantage of this approach is that the anchor point of the 
unknown offender does not need to reside in the vicinity of crime scenes, nor in precisely the same land cover type as those of the anchor points of previously observed offenders. This approach should minimize the "rotten apple" effect to provide a better estimate of the offender's anchor point within the study area.

\subsection{Research Proposal}

This research proposes that a geographic profiling model that formally parameterizes both the spatial interaction and the landscape characteristics of an unknown serial offender will produce more accurate estimates of the anchor point than those from existing techniques. Furthermore, such techniques should be less suceptable to the so-called "rotten apple" effect, thus provide a better estimate of the offender's anchor point across a heterogeneous landscape. To test this hypothesis, traditional and land cover enhanced geographic profiling models will be generated for a random sample of solved serial offenses that occurred in Baltimore, Maryland. The resulting profiles will be used to estimate the location of an offender's anchor point, and will be appraised according to its efficiency in providing a search strategy. Following established evaluation methodologies (e.g., Levine, 2009; Paulsen, 2006a; Rich \& Shively, 2004; Rossmo, 2005; Snook et al., 2005), the efficacy of a geographic profile will be assessed by comparing the accuracy and precision of the estimates produced by each technique.

This hypothesis is conditioned on three assumptions. First, each crime series consists of offenses perpetrated by a single offender. Second, the offender is assumed to have initiated and concluded all criminal activities from a fixed anchor point located within the study area. Finally, the land cover classifications used in this study reflects the actual physical and cultural structures that influenced the offender's behavior in space (i.e., perceptions of opportunity and target attractiveness) as well as the distribution of available targets (i.e., target backcloth).

\section{Data \& Methodology}

The data and methodology employed for this study is organized into three sections. The first part describes the crime and land cover datasets utilized in this investigation. Next, the seven geographic profiling models are described. The final section presents the tests used to assess the modeled estimates.

\subsection{Data}

\subsubsection{Serial Crime Data}

The crime datasets used for this study were comprised of a random sample of 781 solved serial burglary, larceny, and robbery offenses that occurred in Baltimore, MD, between 1993 and 1997. All crime records included crime scene locations attributed to a serial offender. The dataset provided one origin point for each crime series, which is assumed for this research to be the sole anchor point for the crime series. The crimes were comprised of 167 series (burglary $=47$, larceny $=43$, robbery $=77$ ), which averaged 4.68 crimes per series (burglary $=4.40$, larceny $=4.32$, robbery $=5.04)$. The average criminal commute measured $6.79 \mathrm{~km}(\mathrm{SD}=6.88 \mathrm{~km})$ with a median of $4.94 \mathrm{~km}$. For the purpose of this analysis, the Baltimore dataset was split into two randomly assigned groups: the profile and the calibration samples. The profile sample consisted of 263 offenses associated with 52 crime series. The number of crimes per series averaged $5.06(\mathrm{SD}=2.22)$ with a median of 4 (Table 1). The calibration sample was comprised of 518 offenses for 115 crime series. There were an average of $4.50(\mathrm{SD}=1.90)$ and a median of 4 crimes per series (Table 2). A larger calibration sample was chosen to ensure modeling efficiency.

Table 1. Profile sample of Baltimore, MD, serial crimes

\begin{tabular}{|c|c|c|c|c|c|c|c|c|c|c|}
\hline & \multirow{2}{*}{ Count } & \multicolumn{4}{|c|}{ Offenses } & \multicolumn{5}{|c|}{ Journey-to-Crime (km) } \\
\hline & & Sum & mean & stdev & median & mean & stdev & $\min$ & median & $\max$ \\
\hline Burglary: & 11 & 60 & 5.45 & 2.98 & 4 & 5.01 & 6.65 & 0.00 & 1.43 & 22.95 \\
\hline Larceny: & 14 & 60 & 4.29 & 1.20 & 4 & 7.687 & 7.00 & 0.00 & 5.44 & 26.60 \\
\hline Robbery: & 27 & 143 & 5.30 & 2.25 & 4 & 7.732 & 5.202 & 0.33 & 6.71 & 23.56 \\
\hline Totals: & 52 & 263 & 5.06 & 2.22 & 4 & 7.101 & 6.08 & 0.00 & 5.47 & 26.60 \\
\hline
\end{tabular}


Table 2. Calibration sample of Baltimore, MD, serial crimes

\begin{tabular}{lllllllllll}
\hline & \multirow{3}{*}{ Count } & \multicolumn{1}{l}{ Offenses } & \multicolumn{7}{c}{ Journey-to-Crime (km) } \\
& & sum & mean & stdev & median & mean & stdev & min & median & max \\
\hline Burglary: & 36 & 147 & 4.08 & 1.56 & 4 & 5.99 & 9.36 & 0.00 & 1.61 & 52.76 \\
Larceny: & 29 & 126 & 4.34 & 1.72 & 4 & 7.472 & 7.36 & 0.00 & 5.87 & 38.23 \\
Robbery: & 50 & 245 & 4.90 & 2.17 & 4 & 6.613 & 5.539 & 0.00 & 5.64 & 23.94 \\
Totals: & 115 & 518 & 4.50 & 1.90 & 4 & 6.646 & 7.25 & 0.00 & 4.53 & 52.76 \\
\hline
\end{tabular}

\subsubsection{Land Cover Data}

In their earlier study, Kent and Leitner (2009) used land cover data obtained from the 1996 Coastal Change and Analysis Program (C-CAP) developed by the U.S. National Oceanic and Atmospheric Administration (NOAA). The C-CAP products consist of raster-based thematic data indifying land cover and land change information for coastal regions of the United States. The source data consisted of twenty-three generalized land cover classifications derived from 30-meter resolution satellite imagery (NOAA, 1996). The C-CAP data covers the Baltimore, MD, study area for the time period corresponding to the serial crime database. Performance requirements necessitated the aggregation of the land cover dataset from 30 meter to 480 meter cell sizes. Each cell was assigned the statistical mode of the land cover classification. Consequently, the number of usable land cover classes was reduced to eighteen (Figure 1). The resulting coverage contained 12,932 grid cells. The coverage fit the geographic extents of the Baltimore study area.

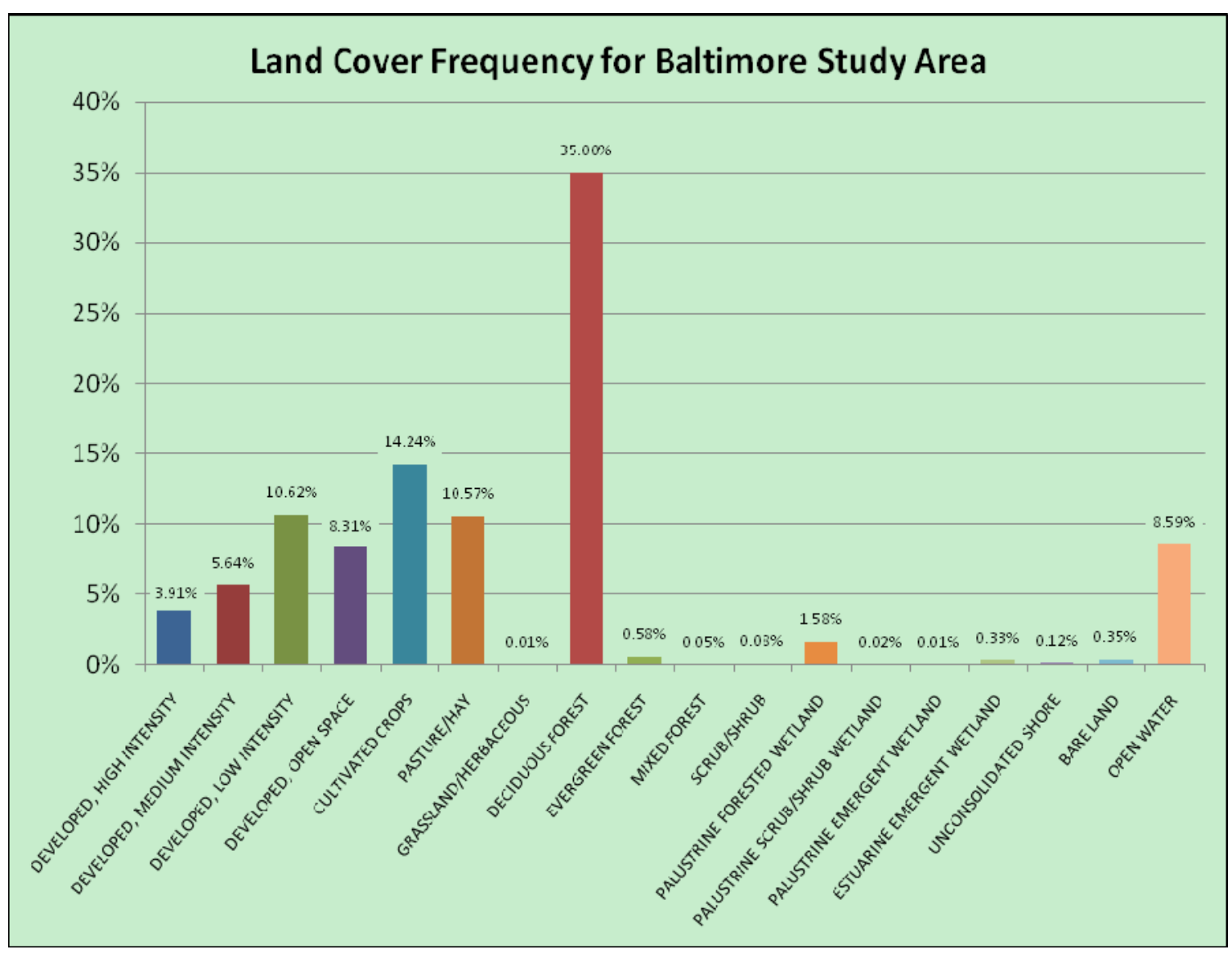

Figure 1. Distribution of aggregated land cover classes in the Baltimore, MD, study area 


\subsection{Geographic Profiling Models}

Seven different geographic profiling methods were chosen to compare the effectiveness of land cover methodologies. The chosen profiling techniques included traditional and landscape enhanced spatial interaction models, which were assessed according to contemporary techniques (Rich \& Shively, 2004). A centrographic profiling technique was also utilized for diagnostic comparisons (Paulsen, 2006b; Levine, 2005; Rossmo, 2005). Details of the seven models are presented in the following text.

\subsubsection{Journey-to-Crime Estimation (JTC)}

The JTC profiling technique estimates the probability of locating an offender's anchor point by applying an empirically calibrated distance decay function to the distribution of linked crime scenes. The decay function is used to assign likelihood values to a density surface encompassing the criminal study area. There are two principal methods for calculating the decay equation. The first method fits a mathematical trend function through a frequency distribution of JTC distances measured for the calibration sample of solved serial crimes. More often than not, this equation belongs to an exponential family of functions (Canter et al., 2000, Rossmo 2000). However, alternate functions have been used (Canter \& Hammond, 2006; Levine, 2007). The second approach uses an interpolation kernel to regress a non-linear function directly through the calibration distribution (Levine, 2007). Once a distance decay function has been determined, it is applied to the distribution of crimes committed by the unknown offender. The result is a probability surface that represents the likelihood of locating an offender's anchor point within the study area.

The calibration sample used to derive the distance decay curve contained 115 solved serial cases (see Table 2). A JTC frequency distribution consisting of 500-meter distance intervals (i.e., bins) was constructed for all incidents in the sample. An exponential function, chosen due to its simplicity and popularity within the geographic profiling literature (e.g., Canter et al., 2000; Canter \& Hammond, 2006; Levine, 2005; 2007), was regressed for the frequency distribution (Figure 2). Although the coefficient of determination was relatively weak, $R^{2}=0.43$, the equation proved to be a significant fit $(\mathrm{F}=96.81, p<0.000)$.

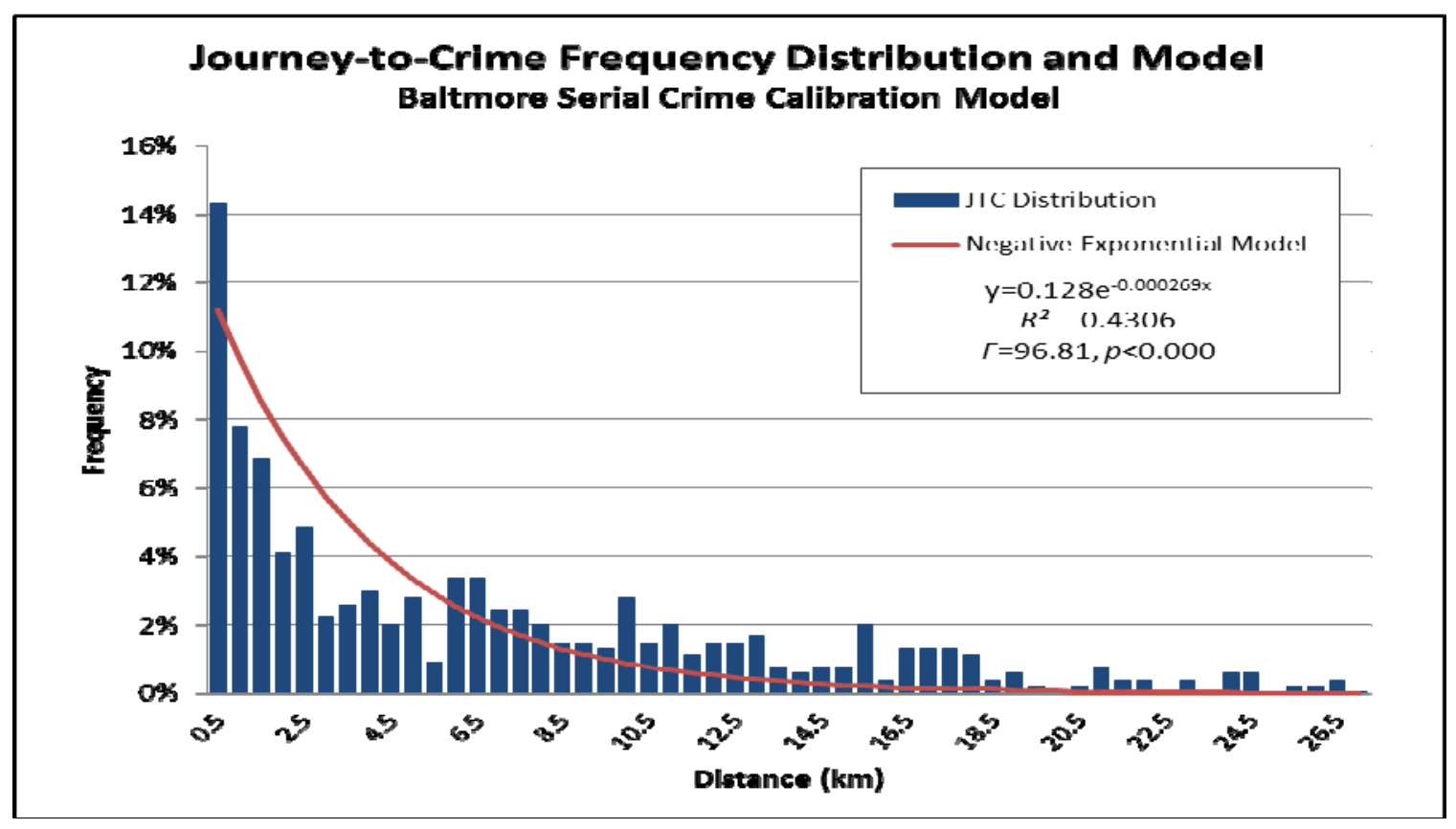

Figure 2. Journey-to-crime frequency distribution and model of the Baltimore, MD, calibration sample

With a decay function defined, the JTC estimate for the profile sample proceeded in four general steps. First, a 480 meter regularly spaced grid consisting of 12,932 cells was placed over the study area. Each grid cell represents the hypothetical probability of containing the anchor point. Second, the Euclidean distance between a cell's centroid and each crime scene was measured for each series. Next, the exponential distance decay function defined by the calibration sample (see Figure 2) was applied to each cell-to-crime distance, and summed over the series to produce a density surface. A cell's modeled output was converted into a probability value by scaling the estimates such that the sum of all cell values equaled 1.0. The resulting surface represents the probability of 
identifying an offender's anchor point according to the distance decay function:

$$
P(J T C)=\sum_{i=1}^{n} f\left(d_{x_{i} z}\right)
$$

Where $d$ is the Euclidean distance measured between each crime scene $x_{\mathrm{i}}$ and grid cell $z$, and the function, $f$, represents the negative exponential decay along each of the distances.

\subsubsection{Bayesian JTC Estimation}

The Bayesian JTC model for predicting the anchor point of a serial offender was first introduced by Levine (2007). The formulation used in this study updates the empirically calculated JTC estimate of the unknown serial offender, $P(J T C)$, using a likelihood function derived from solved serial crimes. The likelihood, $P(O \mid J T C)$, is the conditional probability of an unknown offender's anchor point, $O$, given the anchor point for known offenders that committed crimes in the same locations as the unknown offender. Two Bayesian probability estimates are generated with this approach. The first is the product of the likelihood and prior, what is referred to as the Bayesian JTC Product, which takes the the form:

$$
P(J T C \mid O) \propto P(O \mid J T C) P(J T C)
$$

Where the posterior, $P(J T C \mid O)$, represents the product of the prior JTC estimate updated according to the conditional likelihood of anchor points, $P(O \mid J T C)$. The second probability estimate is the full Bayesian JTC Posterior probability:

$$
P(J T C \mid O)=\frac{P(O \mid J T C) P(J T C)}{P(O)}
$$

Where $P(O \mid J T C)$ is the likelihood estimate of the anchor point location, $P(J T C)$ is the empirically calibrated prior JTC estimate, and $P(O)$ is the marginal probability of all previously solved anchor points within the study area.

Following the methodological approach established by Levine (2007), the conditional likelihood, $P(O \mid J T C)$, was estimated by first identifying those grid cells where the crime scene locations from the profile and calibration samples were coincident. For each coincidence, the distribution of known anchor points from the calibration sample were summed and interpolated onto the study grid as a probability surface using a single kernel density function. An adaptive normal kernel was used, but other functions may be applicable. Probability surfaces were combined and scaled such that the sum of all cell values equaled 1.0. Finally, the product of the likelihood and the prior JTC probability values were calculated for each cell, producing both the Bayesian JTC Product (eq. 2) and the Bayesian JTC Posterior probability estimates (eq. 3).

\subsubsection{Filtered JTC Estimation}

The probability of land cover can be used to exclude those locations that are unlikely to contain an offender's anchor point (Kent \&Leitner, 2009). Accordingly, the frequency of a given land cover category was calculated for all grid cells that were spatially coincident with anchor points of the calibration sample. Of the eighteen land cover categories, only four classes were associated with the anchor points from the calibration sample: Open space and the developed high, medium, and low intensity land cover types. These values constituted the marginal probability of identifying an offender's residence according to a particular land cover type. Accordingly, the Filtered JTC Estimate represents the product of the marginal and JTC probabilities:

$$
P(\text { FilteredJTC })=P(J T C) P(L C)
$$

Where the Filtered JTC Estimate, $P($ FilteredJTC), is equal to the product of the marginal probability of land cover, $P(L C)$, and the prior JTC estimation for a grid cell, $P(J T C)$. The estimate is then scaled for each grid cell such that the sum is equal to 1.0 .

\subsubsection{Land Cover Bayesian JTC Estimations}

This study proposes two new formulations of the empirical Bayesian JTC approach that conditionally updates the empirically derived JTC prior probability given the observance of a particular land cover type. As established earlier, the location of an offender's anchor point is spatially dependent on the surrounding physical and cultural environment. Thus, an offender's residence must be confined to certain land cover characteristics inherent within the study area. Accordingly, posterior probability of a land cover Bayesian estimate can be conditionally related 
to the prior JTC estimate and the probability of observing a given land cover type. This first formulation and takes on the form:

$$
P(Z \mid L C)=\frac{P(L C \mid Z) P(J \quad T C)}{\sum_{i=1}^{n} P\left(L C \mid Z_{i}\right) P\left(Z_{i}\right)}
$$

Where each term of the Bayesian equation is defined as:

- $P(Z \mid L C)$ is the Land Cover Bayesian Posterior probability of the offender's anchor point estimate, $\mathrm{Z}$, given a particular land cover type, LC.

- $P(L C \mid Z)$ is the conditional probability of land cover given a known offender's anchor point. This value represents the likelihood that a particular land cover class would be observed in the presence of the offender's actual residence.

- $P(J T C)$ represents the empirically estimated JTC prior probability of an offender's anchor point.

- The denominator is the marginal probability of land cover for each grid cell in the study area, and is derived using the known anchor points maintained in the calibration sample. The denominator acts as a normalizing constant to the Bayesian function, which may also be represented as the total probability of land cover for known offenders, $P(L C)$.

The second estimate is the Land Cover Bayesian Product, which represents the product of the conditional and prior probability (i.e., the numerator in Equation 5). This estimate is calculated independently of the marginal distribution (i.e., the denominator), and takes on the form:

$$
P(Z \mid L C) \propto P(L C \mid Z) P(J T C)
$$

Where the Land Cover Bayesian Product, $P(Z \mid L C)$, is proportional to the product of the likelihood, $P(L C \mid Z)$, and the empirical prior, $P(J T C)$, probability values. This formulation provides the relative weights of a JTC estimate updated using land cover values observed for offenders in the calibration sample.

To calculate both the Land Cover Bayesian Posterior and Product, the conditional probability of land cover given the anchor point of known offenders was estimated. The routine first identified those grid cells in which crime scenes for the unknown offender were spatially coincided with crime scenes of known offenders. For each coincident pair, the distribution of land cover classes for each of the selected calibration anchor points were summed and interpolated onto the study grid as a probability surface using a kernel function. The kernel was derived using a negative exponential function. The conditional probability surfaces were combined and scaled such that the sum of all cell values equaled 1.0. The rationale for using a negative exponential function ensures that the area immediately surrounding the coincident anchor points will adequately represent the actual land cover, which was necessary given that the land cover data was aggregated from 30 meter to 480 meter grid cells. Additionally, the rapid decay and skew of the exponential kernel guaranteed that the land cover corresponding to the anchor points are not overly inclusive or exclusive.

\subsubsection{Center of Minimum Distance}

Spatial distributions strategies based on centrographic measures are founded on the principle of least effort and often utilized in geographic profiling studies as a diagnostic routine for comparing model efficacy (e.g., Levine, 2005; Paulsen, 2006a; Snook et al., 2005). Because of its simplicity and intuitive implementation, the center of minimum distance (CMD) has become a popular measure for predicting the anchor point location relative to the distribution of crime scenes. The CMD is iteratively defined as a point within the study area where the sum of the distance to all other crime locations is smallest (Levine, 2007):

$$
C M D=\sum_{i=1}^{n} d_{\min }\left(x_{i}, C M D_{\bar{x}}\right)
$$

Where the function $d_{\min }$ represents the minimum distance between the crime scene, $x$, at location $i$, and the current center of minimum distance, $C_{x}$ for the distribution. In contrast to the six JTC routines described above, the CMD estimate produces a single point to indicate the predicted anchor point. Accordingly, this routine is vulnerable to outliers that can distort the results. Furthermore, the single point produced by the default output of the CMD estimate is generally incompatible with evaluation routines that assess performance according to search costs (Levine, 2009). Accordingly, the CMD is used to provide a limited search area based on the distance 
between the predicted and actual anchor points.

\subsection{Evaluation Techniques}

The seven profiling models evaluated for this study were compared using techniques that measure a profile's ability to accurately and precisely locate the anchor point of offenders in the profile sample dataset. A review of contemporary literature reveals multiple techniques for assessing a criminal geographic profiling model efficacy (Rich \& Shively, 2004). While some of these measures are controversial (see Levine, 2005 and Rossmo, 2005), three of the most commonly used assessment techniques were chosen for this study: profile probability value, error distance, and search cost.

\subsubsection{Profile Probability Value}

This technique assesses accuracy according to the probability assigned to the grid cell in which the true anchor point is located. Comparable to a search score, higher probability values indicate the likelihood of identifying the offender's anchor point within a grid cell. Because the CMD technique does not produce a probability estimate, it is excluded from this evaluation technique.

\subsubsection{Error Distance}

Primarily used as a hind-cast or back-testing tool, this evaluation technique assesses accuracy according to the Euclidean distance between the predicted and the true anchor point (Levine, 2007; Snook et al., 2005). Shorter error distances indicate a more accurate model. In many ways, this routine can provide a running diagnostic when comparing multiple profiling routines. This evaluation technique was applied to all seven profiling models.

\subsubsection{Search Cost}

This technique calculates the proportion of the study area that must be searched in order to identify the offender's anchor point (e.g., Canter et al., 2000; Levine, 2009; and Rossmo, 2000). Search cost is equal to the number of grid cells that must be searched before identifying the offender's true anchor point. Accordingly, fewer cells indicate higher precision and smaller search costs. By default, the CMD model returns a point estimate, which is incapable of generating a search cost without modification (Paulsen, 2006a; Levine, 2005; Rossmo, 2005). A comparable CMD estimate was derived by counting the number of grid cells that fall inside a circle defined by a radius equal to the error distance. However, such a measure is only an enumeration, and cannot be interpreted in the context of a probability surface.

\section{Results}

The results generated for the seven geographic profiling models and their subsequent evaluations are summarized in Table 3. The overall performance of each model is organized by evaluation criteria. Individual comparisons for each evaluation technique are provided in Tables 4, 5, and 6 . These tables detail how often a model performed as well or better than other techniques.

Results were compared using two non-parametric tests. First, the Friedman test was applied to the entire group and used to determine if the modeled output was different across each measure. The second test compared the pairwise differences between each model using the Wilcoxon signed-rank test for related samples. Because comparisons are not interpreted collectively, the acceptance or rejection of the null hypothesis for each comparison is of more interest when examined individually. Accordingly, Bonferroni adjustments, often applied for multiple comparisons, were deemed inappropriate for this study (Feise, 2002; Rothman, 1990). 
Table 3. Geographic profile model evaluation results

\begin{tabular}{|c|c|c|c|c|c|c|c|c|c|}
\hline \multirow{3}{*}{ Model } & \multirow{2}{*}{\multicolumn{3}{|c|}{$\begin{array}{c}\text { Profile Probability Value } \\
\text { Larger is better }\end{array}$}} & \multirow{2}{*}{\multicolumn{3}{|c|}{$\begin{array}{c}\text { Error Distance (meters) } \\
\text { Smaller is better }\end{array}$}} & \multirow{2}{*}{\multicolumn{3}{|c|}{$\begin{array}{c}\text { Search Cost } \\
\text { Smaller is better }\end{array}$}} \\
\hline & & & & & & & & & \\
\hline & Mean (sd) & Median & $\begin{array}{c}\text { Freidman } \\
\text { Rank }^{\mathrm{a}}\end{array}$ & Mean (sd) & Median & $\begin{array}{c}\text { Freidman } \\
\text { Rank }^{b}\end{array}$ & Mean (sd) & Median & $\begin{array}{c}\text { Freidman } \\
\operatorname{Rank}^{\mathrm{c}}\end{array}$ \\
\hline $\begin{array}{c}\text { JTC } \\
\text { Estimate }\end{array}$ & $\begin{array}{l}0.000914 \\
(0.00072)\end{array}$ & 0.000645 & 2.44 & $\begin{array}{c}6,137.25 \\
(5,086.48)\end{array}$ & $5,275.94$ & 3.80 & $\begin{array}{c}708.06 \\
(1,177.9)\end{array}$ & 301.00 & 4.13 \\
\hline $\begin{array}{c}\text { Filtered JTC } \\
\text { Estimate }\end{array}$ & $\begin{array}{l}\underline{\mathbf{0 . 0 0 2 2 5 9}} \\
(0.00275)\end{array}$ & $\underline{0.001561}$ & $\underline{4.46}$ & $\frac{\mathbf{6 , 1 0 1 . 8 5}}{(5,103.89)}$ & $5,556.52$ & 3.82 & $\begin{array}{c}597.25 \\
(1,354.4)\end{array}$ & $\underline{149.50}$ & $\underline{3.03}$ \\
\hline $\begin{array}{c}\text { Bayesian JTC } \\
\text { Product }\end{array}$ & $\begin{array}{l}0.002249 \\
(0.00284)\end{array}$ & 0.000849 & 3.86 & $\begin{array}{c}6,957.30 \\
(6,093.01)\end{array}$ & $6,076.35$ & $\underline{3.66}$ & $\begin{array}{l}1,215.56 \\
(2,173.4)\end{array}$ & 350.50 & 3.84 \\
\hline $\begin{array}{c}\text { Bayesian JTC } \\
\text { Posterior }\end{array}$ & $\begin{array}{l}0.001352 \\
(0.00171)\end{array}$ & 0.000530 & 2.65 & $\begin{array}{c}7,144.67 \\
(5,971.78)\end{array}$ & $6,278.36$ & 4.38 & $\begin{array}{l}1,323.17 \\
(2,141.2)\end{array}$ & 490.00 & 5.11 \\
\hline $\begin{array}{c}\text { Land Cover } \\
\text { Bayesian } \\
\text { Product }\end{array}$ & $\begin{array}{l}0.001918 \\
(0.00203)\end{array}$ & 0.001202 & 4.11 & $\begin{array}{c}6,673.18 \\
(5,783.85)\end{array}$ & $5,058.01$ & 4.39 & $\frac{\mathbf{4 5 1 . 1 9}}{(753.1)}$ & 188.00 & 3.28 \\
\hline $\begin{array}{c}\text { Land Cover } \\
\text { Bayesian } \\
\text { Posterior }\end{array}$ & $\begin{array}{l}0.001524 \\
(0.00171)\end{array}$ & 0.000968 & 3.48 & $\begin{array}{c}6,243.71 \\
(5,408.78)\end{array}$ & $\underline{4,836.40}$ & 4.01 & $\begin{array}{l}537.33 \\
(808.3)\end{array}$ & 229.00 & 3.60 \\
\hline $\begin{array}{l}\text { Center of } \\
\text { Minimum } \\
\text { Distance }\end{array}$ & - & - & - & $\begin{array}{c}6,104.70 \\
(5,048.72)\end{array}$ & $5,543.07$ & 3.94 & $\begin{array}{c}867.54 \\
(1,252.8)\end{array}$ & 472.00 & 5.03 \\
\hline
\end{tabular}

\section{Friedman Test Statistics, $N=52$}

a) $\chi^{2}=48.573, d f=5, \mathrm{p} \leq 0.000$ (Asymp. Sig.)

b) $\chi^{2}=5.626, d f=6, p \leq 0.466$ (Asymp. Sig.)

c) $\chi^{2}=44.518, d f=6, p \leq 0.000$ (Asymp. Sig.)
Friedman Mean Ranks:

a) Filtered JTC $>$ Land Cover Bayesian Product $>$ Bayesian JTC Product $>$ Land Cover Bayesian Posterior $>$ Bayesian JTC Posterior $>$ JTC Estimate

b) Bayesian JTC Product $<$ JTC Estimate $<$ Filtered JTC Estimate $<$ CMD $<$ Land Cover Bayesian Posterior $<$ Bayesian JTC Posterior $<$ Land Cover Bayesian Posterior

c) Filtered JTC Estimate $<$ Land Cover Bayesian Product $<$ Land Cover Bayesian Posterior $<$ Bayesian JTC Product $<$ JTC Estimate $<$ CMD $<$ Bayesian JTC Posterior

\subsection{Profile Probability Value}

Profile probability values denote the probability of identifying the offender's anchor point for a given location. Larger probability estimates indicate a greater likelihood of the anchor point. The CMD routine does not produce a probability estimate and was not assessed for this measure. As revealed in Table 3, the Filtered JTC Estimate produced the highest mean $(0.002259)$ and median $(0.001561)$ probability estimates of all 52 profiles. Model estimates were ranked and compared using the Friedman test. Higher ranks equates to better model performance. The Filtered JTC Estimate was ranked highest of all the estimates calculated for the profile sample. The Bayesian JTC Product was assigned the second highest average probability, while the Land Cover Bayesian Product had the second highest median value. With the exception of the traditional JTC Estimate, all models were found to have relatively large variances. Results of the Friedman statistics for the modeled output indicate significant differences between the six estimates.

Performance assessed using the pairwise comparisons of the profile probability values are provided in Table 4. A model's success or failure corresponds with the Wilcoxon signed-rank output of positive, negative, and tied comparisons. The matrix reveals the number of times a particular profiling technique was ranked as better, worse, or equal to the other techniques analyzed. Higher ranks equate to better performance. A tie occurred whenever two models estimated an offender's residence an equal number of times. Analogous to the results observed from the Friedman test, the Filtered JTC estimate was the most accurate for 180 of the 260 comparisons $(69.2 \%)$. The 
poorest comparative performance was observed for the JTC Estimate, which had a success rate of 75 of 260 (28.8\%). Overall, the three land cover enhanced techniques were ranked in the top four most successful estimates, along with the Bayesian JTC Product estimate. In some instances, significance between modeled output was elusive. For example, the Filtered JTC and Bayesian JTC Product estimates were ranked the highest an equal number of times (26 each), resulting in no significant difference in performance. Similarly, the Land Cover Bayesian Product estimates were not significantly different from the Filtered JTC or the Bayesian JTC Product.

\subsection{Error Distance}

The profiled error distance represents the Euclidean distance measured between the predicted and true location of an anchor point. Smaller error distances equate to more accurate profiles. As indicated in Table 3, the Filtered JTC Estimate produced the smallest average error distance of all techniques, while the Land Cover Bayesian Posterior produced the smallest median distance $(6.10 \mathrm{~km}$ and $4.84 \mathrm{~km}$, respectfully). The CMD and JTC Estimate also had low mean error distances, while the median distance for the Land Cover Bayesian Product was the second shortest in this sample. For this evaluation technique, the Friedman test compared and ranked the error distances measured for each model. Because shorter distances indicate better performance, ranks were assigned in ascending order. The lowest mean rank difference of 3.66 was assigned to the Bayesian JTC Product model. The error distances for this model were frequently shorter than those produced by other techniques. Conversely, the Land Cover Bayesian JTC Product ranked last in the comparisons (rank $=4.39$ ), which indicates that this technique, on average, produced error distances that were frequently longer when compared to the other techniques. The Friedman tests reveal that the ranked distribution of scores was not significantly different.

The pairwise comparisons in Table 5 represents the number of times a particular model produced the shortest (better), farthest (worse), or equal (tie) error distance when compared to all other estimates. As indicated, the Bayesian JTC Product and JTC Estimation models produced more estimates with error distances equal to or shorter than those produced by the other techniques, 188 (60.26\%) and 187 (59.94\%), respectively. The Filtered JTC Estimate was third best, producing equal or shorter error distances for 179 of 312 (57.37\%) estimates. And like the results from the Friedman ranks, the two worst performing models included the Bayesian JTC Posterior (148 of 312) and Land Cover Bayesian Product (146 of 312). The Wilcoxon z-tests were unable to confirm significance for any of the pairwise comparisons.

\subsection{Search Costs}

Search cost quantifies the proportion of the study area that must be searched in order to locate the anchor point. Accordingly, profile estimates that require fewer grid cells signify higher precision. In order to compare output with CMD routine, a comparable search cost was derived. Table 3 reveals that the land cover enhanced models performed better than the other techniques. Estimates generated from the Land Cover Bayesian JTC Product models required the smallest average search cost, 451.19 grid cells $($ median $=188)$, while the Filtered JTC Estimate models required a median cost of 149.5 (mean=597.25). The Land Cover Bayesian JTC Posterior followed, with an average and median search cost of 537.33 and 229 grid cells, respectively.

Friedman test found the Filtered JTC Estimate to be the best performing model (see Table 3). In all, the Friedman test confirmed significant differences between the modeled outputs.

Table 6 depicts the results of theWilcoxon signed rank tests. Model efficacy is ranked in ascending order of search cost. The top three performing models incorporate land cover within its framework: Filtered JTC Estimate, Land Cover Bayesian Product, and Land Cover Bayesian Posterior (66.9\%, 62.2\%, and 58\%, respectively). Indeed, each of these three techniques exhibited significant performance gains over the traditional JTC Estimates and Bayesian JTC Posterior. The highest performing model was assigned to the Filtered JTC Estimate, which had a pairwise ranking of 209 equal or better outcomes. In terms of the lowest performance, the Bayesian JTC Posterior was consistently surpassed by the other six models, having produced only 102 (32.7\%) estimates that were equal or better than the other techniques. This model was slightly outperformed by the CMD estimate, which had 105 equal or better estimates (33.7\%). However, the Wilcoxon z-test was unable to assign significance for various combinations of modeled comparisons. 
Table 4. Wilcoxon signed-rank test for pairwise comparisons of modeled profile probability value

\begin{tabular}{|c|c|c|c|c|c|c|c|c|}
\hline & & $\begin{array}{c}\text { JTC } \\
\text { Estimate } \\
\end{array}$ & $\begin{array}{c}\text { Filtered JTC } \\
\text { Estimate } \\
\end{array}$ & $\begin{array}{c}\text { Bayesian } \\
\text { JTC Product }\end{array}$ & $\begin{array}{c}\text { Bayesian JTC } \\
\text { Posterior } \\
\end{array}$ & $\begin{array}{c}\text { Land Cover Bayesian } \\
\text { Product }\end{array}$ & $\begin{array}{c}\text { Land Cover Bayesian } \\
\text { Posterior } \\
\end{array}$ & $\begin{array}{c}\text { Sum } \\
(\mathrm{n}=260)\end{array}$ \\
\hline \multirow{5}{*}{$\begin{array}{c}\text { JTC } \\
\text { Estimate }\end{array}$} & Success & \multirow{4}{*}{--} & 7 & 22 & 25 & 11 & 10 & 75 \\
\hline & Failure & & 45 & 30 & 27 & 41 & 42 & 185 \\
\hline & Tie & & 0 & 0 & 0 & 0 & 0 & 0 \\
\hline & P-Value & & 0.000 & 0.001 & 0.055 & 0.000 & 0.000 & \\
\hline & Success & 45 & \multirow{4}{*}{-- } & 26 & 39 & 32 & 38 & 180 \\
\hline \multirow{3}{*}{$\begin{array}{l}\text { Filtered JTC } \\
\text { Estimate }\end{array}$} & Failure & 7 & & 26 & 13 & 20 & 14 & 80 \\
\hline & Tie & 0 & & 0 & 0 & 0 & 0 & 0 \\
\hline & P-Value & 0.000 & & 0.953 & 0.003 & 0.061 & 0.000 & \\
\hline \multirow{4}{*}{$\begin{array}{l}\text { Bayesian } \\
\text { JTC Product }\end{array}$} & Success & 30 & 26 & \multirow{4}{*}{-- } & 36 & 24 & 28 & 144 \\
\hline & Failure & 22 & 26 & & 8 & 27 & 24 & 107 \\
\hline & Tie & 0 & 0 & & 8 & 1 & 0 & 9 \\
\hline & P-Value & 0.001 & 0.953 & & 0.000 & 0.459 & 0.061 & \\
\hline \multirow{4}{*}{$\begin{array}{l}\text { Bayesian } \\
\text { JTC } \\
\text { Posterior }\end{array}$} & Success & 27 & 13 & 8 & \multirow{4}{*}{--} & 14 & 20 & 82 \\
\hline & Failure & 25 & 39 & 36 & & 38 & 32 & 170 \\
\hline & Tie & 0 & 0 & 8 & & 0 & 0 & 8 \\
\hline & P-Value & 0.055 & 0.003 & 0.000 & & 0.006 & 0.236 & \\
\hline \multirow{4}{*}{$\begin{array}{c}\text { Land Cover } \\
\text { Bayesian } \\
\text { Product }\end{array}$} & Success & 41 & 20 & 27 & 38 & \multirow{4}{*}{-- } & 35 & 161 \\
\hline & Failure & 11 & 32 & 24 & 14 & & 17 & 98 \\
\hline & Tie & 0 & 0 & 1 & 0 & & 0 & 1 \\
\hline & P-Value & 0.000 & 0.061 & 0.459 & 0.006 & & 0.000 & \\
\hline \multirow{4}{*}{$\begin{array}{l}\text { Land Cover } \\
\text { Bayesian } \\
\text { Posterior }\end{array}$} & Success & 42 & 14 & 24 & 32 & 35 & \multirow{4}{*}{-- } & 147 \\
\hline & Failure & 10 & 38 & 28 & 20 & 17 & & 113 \\
\hline & Tie & 0 & 0 & 0 & 0 & 0 & & 0 \\
\hline & P-Value & 0.000 & 0.000 & 0.061 & 0.236 & 0.000 & & \\
\hline
\end{tabular}

Table 5. Wilcoxon signed-rank test for pairwise comparisons of modeled error distance

\begin{tabular}{|c|c|c|c|c|c|c|c|c|c|}
\hline & & $\begin{array}{c}\text { JTC } \\
\text { Estimate }\end{array}$ & $\begin{array}{l}\text { Filtered JTC } \\
\text { Estimate }\end{array}$ & $\begin{array}{c}\text { Bayesian JTC } \\
\text { Product }\end{array}$ & $\begin{array}{c}\text { Bayesian JTC } \\
\text { Posterior }\end{array}$ & $\begin{array}{c}\text { Land Cover } \\
\text { Bayesian } \\
\text { Product }\end{array}$ & $\begin{array}{c}\text { Land Cover } \\
\text { Bayesian Posterior }\end{array}$ & CMD & $\underset{(\mathrm{n}=312)}{\text { Sum }}$ \\
\hline \multirow{3}{*}{ JTC Estimate } & Success & \multirow{3}{*}{--} & 19 & 18 & 25 & 28 & 25 & 31 & 146 \\
\hline & Tie & & 12 & 11 & 9 & 3 & 6 & 0 & 41 \\
\hline & P-Value & & 0.925 & 0.591 & 0.108 & 0.227 & 0.731 & 0.089 & \\
\hline \multirow{2}{*}{$\begin{array}{l}\text { Filtered JTC } \\
\text { Estimate }\end{array}$} & Success & 21 & \multirow{2}{*}{--} & 22 & 27 & 28 & 25 & 29 & 152 \\
\hline & P-Value & 0.925 & & 0.622 & 0.126 & 0.313 & 0.433 & 0.591 & \\
\hline \multirow{4}{*}{$\begin{array}{c}\text { Bayesian JTC } \\
\text { Product }\end{array}$} & Success & 23 & 27 & \multirow{4}{*}{--} & 26 & 26 & 28 & 29 & 159 \\
\hline & Failure & 18 & 22 & & 17 & 22 & 22 & 23 & 124 \\
\hline & Tie & 11 & 3 & & 9 & 4 & 2 & 0 & 29 \\
\hline & P-Value & 0.591 & 0.622 & & 0.391 & 0.854 & 0.703 & 0.597 & \\
\hline \multirow{4}{*}{$\begin{array}{c}\text { Land Cover } \\
\text { Bayesian } \\
\text { Product }\end{array}$} & Success & 21 & 21 & 22 & 28 & \multirow{4}{*}{-- } & 14 & 19 & 125 \\
\hline & Failure & 28 & 28 & 26 & 23 & & 28 & 33 & 166 \\
\hline & Tie & 3 & 3 & 4 & 1 & & 10 & 0 & 21 \\
\hline & P-Value & 0.227 & 0.313 & 0.854 & 0.303 & & 0.242 & 0.111 & \\
\hline \multirow{4}{*}{$\begin{array}{l}\text { Land Cover } \\
\text { Bayesian } \\
\text { Posterior }\end{array}$} & Success & 21 & 20 & 22 & 28 & 28 & \multirow{4}{*}{-- } & 23 & 142 \\
\hline & Failure & 25 & 25 & 28 & 22 & 14 & & 29 & 143 \\
\hline & Tie & 6 & 7 & 2 & 2 & 10 & & 0 & 27 \\
\hline & P-Value & 0.731 & 0.433 & 0.703 & 0.138 & 0.242 & & 0.402 & \\
\hline \multirow{4}{*}{ CMD } & Success & 21 & 23 & 23 & 30 & 33 & 29 & \multirow{4}{*}{--} & 159 \\
\hline & Failure & 31 & 29 & 29 & 22 & 19 & 23 & & 153 \\
\hline & Tie & 0 & 0 & 0 & 0 & 0 & 0 & & 0 \\
\hline & P-Value & 0.089 & 0.591 & 0.597 & 0.099 & 0.111 & 0.402 & & \\
\hline
\end{tabular}


Table 6. Wilcoxon signed-rank test for pairwise comparisons of modeled search cost

\begin{tabular}{|c|c|c|c|c|c|c|c|c|c|}
\hline & & $\begin{array}{c}\text { JTC } \\
\text { Estimate }\end{array}$ & $\begin{array}{c}\text { Filtered JTC } \\
\text { Estimate }\end{array}$ & $\begin{array}{c}\text { Bayesian JTC } \\
\text { Product }\end{array}$ & $\begin{array}{c}\text { Bayesian JTC } \\
\text { Posterior }\end{array}$ & $\begin{array}{c}\text { Land Cover } \\
\text { Bayesian Product }\end{array}$ & $\begin{array}{c}\text { Land Cover } \\
\text { Bayesian } \\
\text { Posterior }\end{array}$ & CMD & $\begin{array}{c}\text { Sum } \\
(\mathrm{n}=312)\end{array}$ \\
\hline \multirow{5}{*}{$\begin{array}{c}\text { JTC } \\
\text { Estimate }\end{array}$} & Success & & 14 & 25 & 32 & 18 & 20 & 36 & 145 \\
\hline & Failure & \multirow{3}{*}{--} & 36 & 24 & 20 & 34 & 30 & 14 & 158 \\
\hline & Tie & & 2 & 3 & 0 & 0 & 2 & 2 & 9 \\
\hline & P-Value & & 0.001 & 0.474 & 0.033 & 0.002 & 0.020 & 0.004 & \\
\hline & Success & 36 & \multirow{4}{*}{--} & 28 & 38 & 29 & 31 & 42 & 204 \\
\hline \multirow{4}{*}{$\begin{array}{c}\text { Filtered JTC } \\
\text { Estimate }\end{array}$} & Failure & 14 & & 23 & 14 & 23 & 20 & 9 & 103 \\
\hline & Tie & 2 & & 1 & 0 & 0 & 1 & 1 & 5 \\
\hline & P-Value & 0.001 & & 0.124 & 0.000 & 0.407 & 0.043 & 0.000 & \\
\hline & Success & 24 & 23 & \multirow{4}{*}{-- } & 38 & 22 & 21 & 30 & 158 \\
\hline \multirow{3}{*}{$\begin{array}{c}\text { Bayesian } \\
\text { JTC Product }\end{array}$} & Failure & 25 & 28 & & 8 & 30 & 29 & 21 & 141 \\
\hline & Tie & 3 & 1 & & 6 & 0 & 2 & 1 & 13 \\
\hline & P-Value & 0.474 & 0.124 & & 0.000 & 0.061 & 0.111 & 0.899 & \\
\hline \multirow{4}{*}{$\begin{array}{l}\text { Bayesian } \\
\text { JTC } \\
\text { Posterior }\end{array}$} & Success & 20 & 14 & 8 & \multirow{4}{*}{-- } & 15 & 14 & 24 & 95 \\
\hline & Failure & 32 & 38 & 38 & & 37 & 37 & 28 & 210 \\
\hline & Tie & 0 & 0 & 6 & & 0 & 1 & 0 & 7 \\
\hline & P-Value & 0.033 & 0.000 & 0.000 & & 0.000 & 0.001 & 0.196 & \\
\hline \multirow{4}{*}{$\begin{array}{l}\text { Land Cover } \\
\text { Bayesian } \\
\text { Product }\end{array}$} & Success & 34 & 23 & 30 & 37 & \multirow{4}{*}{-- } & 32 & 37 & 193 \\
\hline & Failure & 18 & 29 & 22 & 15 & & 19 & 15 & 118 \\
\hline & Tie & 0 & 0 & 0 & 0 & & 1 & 0 & 1 \\
\hline & P-Value & 0.002 & 0.407 & 0.061 & 0.000 & & 0.008 & 0.000 & \\
\hline \multirow{4}{*}{$\begin{array}{c}\text { Land Cover } \\
\text { Bayesian } \\
\text { Posterior }\end{array}$} & Success & 30 & 20 & 29 & 37 & 19 & & 38 & 173 \\
\hline & Failure & 20 & 31 & 21 & 14 & 32 & \multirow{3}{*}{-- } & 13 & 131 \\
\hline & Tie & 2 & 1 & 2 & 1 & 1 & & 1 & 8 \\
\hline & P-Value & 0.020 & 0.043 & 0.111 & 0.001 & 0.008 & & 0.000 & \\
\hline \multirow{4}{*}{ CMD } & Success & 14 & 9 & 21 & 28 & 15 & 13 & & 100 \\
\hline & Failure & 36 & 42 & 30 & 24 & 37 & 38 & & 207 \\
\hline & Tie & 2 & 1 & 1 & 0 & 0 & 1 & & 5 \\
\hline & P-Value & 0.004 & 0.000 & 0.899 & 0.196 & 0.000 & 0.000 & & \\
\hline
\end{tabular}

\section{Discussion}

The efficacy of incorporating land cover within geographic proifling models has been validated for two of the three evaluation techniques: profile probability and search costs. Land cover characteristics associated with the anchor points of 115 known serial offenders residing in the Baltimore, MD, were parameterized for use in traditional and Baysian geographic profiling models. In doing so, land cover models were able to reduce the bias associated with clustered anchor points and effectively filter out land use classes that were unlikely to retain the offender's anchor point. Based on these findings, this revised approach to modeling a criminal's behavior in space has significantly improved the probability estimates and lowered the search costs associated with predicting the anchor point of an unknown serial offender.

The output generated by the four contemporary and three land cover enhanced models were assessed according to profile probability, error distance, and search cost. The profile probability evaluation routine measured the strength of a model's ability to predict the anchor point. Of the profile probability models compared, the three land cover enhanced techniques ranked in the top four (see Table 3). As depicted in the pairwise comparisons of Table 4, the land cover Filtered JTC Estimation produced the more successful estimates than all other models (69.2\%), while the two Land Cover Bayesian estimates followed, producing 162 (62.3\%) and 147 (56.5\%) equal or better performing estimates. Although some of the pairwise comparisons exhibited significant differences in performance, it is worth noting the lack of significance between the different Bayesian and Land Cover Bayesian models, which suggests that these two techniques produce very similar results.

Despite finding that the Filtered JTC and Land Cover Bayesian Posterior techniques produced the shortest mean and median error distances, the Bayesian JTC Product was ranked at the top of the error distances criterion, followed by the JTC Estimate (Table 3). Error distances for the Land Cover Filtered technique was ranked third, 
and the remaining two land cover estimates ranked low according to the Friedman test. When compared individually, the Bayesian JTC Product was more efficient at a $60.3 \%$ success rate, which was followed closely by the JTC Probability estimate (see Table 5). However, both the group and individual comparisons proved statistically inconclusive. This lack of significance validates existing criticisms of error distances as a technique that is often incapable of accurately assessing the inherently non-linear mechanics of a geographic profile (Rossmo, 2005).

The last procedure for assessing modeled output was the search cost evaluation. This technique is arguably the best indicator for assessing a model's precision (Levine, 2005; 2007; Rossmo, 2000, 2005). Groupwise comparisons provided in Table 3 reveal that all three lands cover enhanced models produced estimates that had the lowest mean and median search costs. As noted in Table 6, the Land Cover Filtered JTC model had a pairwise success rate of $66.9 \%$ (209), followed by the Land Cover Bayesian Product and Posterior at $62.2 \%$ (194) and $58.0 \%(181)$, respectively. However, the lack of significant difference between some estimates, including the Land Cover Filtered JTC and Land Cover Bayesian Product, indicate that these models performed nearly identically. Accordingly, further evaluation is warranted with a larger datasets.

While the land cover enhanced Bayesian approach is an improvement over contemporary models, the success of this technique is tempered by the performance exhibited by the Filtered JTC Estimates. These results can be explained according to the way the models are constructed. Recall that the JTC distribution represents a maximum likelihood estimate of the unknown offender's anchor point (Levine, 2005). Similarly, the land cover probability estimates are interpreted as the most likely land cover type for an offender's anchor point. Whenever the modes of these two distributions spatially intersect, the modeled output produces a maximum likelihood estimate of the unknown anchor point that is more accurate and precise than any other estimate.

As a consequence, these optimal distributions are found to be geographically dependent. By leveraging this implicit bias, the model's performance is inherently improved; a condition that was observed for more than twenty results. However, this bias is susceptible to the "rotten apple" effect. Specifically, if either the JTC or the land cover estimates fail to produce an optimized estimation, the resulting model will produce an inaccurate estimate. This condition can occur whenever the unknown offender initiates crimes for a location other than those used by offenders in the calibration sample.

This "rotten apple" scenario is best illustrated by comparing Figures 3 and 4 , in which the probability surfaces for the anchor point of a serial larceny is presented using traditional, and filtered JTC estimation techniques, respectively. The JTC Estimation produces a search cost of 879 grid cells. But as illustrated in Figure 4, the search cost for the Filtered JTC estimate was 4,611 grid cells. The Filtered JTC estimate, which typically performs better than the JTC estimate, suffers from a miss-assigned land cover probability estimate. To compensate for this effect, a Bayesian formulation was implemented. As noted for Equation 6, the conditional probability of land cover for the anchor point parameter was calculated using an exponential kernel function. This approach represents a functionally pragmatic approach for optimizing the conditional land cover probability for the area surrounding a known offender's anchor point. Accordingly, Figures 5 and 6 illustrate the Bayesian product (eq. 6) and posterior (eq.5) probabilities for the same criminal. For the Bayesian product, the effect of a miss-assigned land cover estimate is reduced, producing a search cost of 719 . When normalized for all possible land cover scenarios, the Bayesian posterior model produced an imporved estimate of 506 grid cells. By reformulating the joint probability of the JTC prior and land cover likelihood according to a Bayesian framework, this model was able to uniquely compensate for errors that can over and under estimate an offender's anchor point. Simply put, incorporating land cover within a Bayesian formulation makes the geographi profile more tolerant to the "rotten apple" effect. Thus, it produces a more robust estimate of the anchor point. While the overall performance was not as strong (see Tables 3-6), the Bayesian formulation appears to represent a more suitable technique for accommodating the intrinsic geographical biases that define the unknown offender's activity space.

Despite these successes, problems remain. Concerns identified in previous studies remain unaddressed. For instance, some have critized the over reliance on calibrated distance decay functions when modeling a criminal's spatial behavior (Smith et al., 2009). This caveat of ecological fallacy warns that the aggregated distance decay pattern derived from the calibration sample cannot be considered statistically independent, and thus may not be suitable for inferring behavior characteristics on a crime series other than those of the calibration sample. A possible resolution to this issue would be to disaggregate the JTC characteristics of the calibration sample, and identify a common set of commuting trends based on the individual crime series. While compelling, real-world criminal investigations are a priori unaware of the offender's behavior in space, thus making the aggregated approach using a mathematical decay equation a practical and cost effective solution for characterizing the 
offender mobility patterns (Capone \& Nichols, 1975; 1976; Rengert et al., 1999).

A further critique relates to the spatial resolution of the Baltimore study grid. In order to accommodate both computational and operational limitations, the cells in the study grid were enlarged to $480 \mathrm{~m}$ squared. The large cell size made the model estimations proceed faster than cells maintained at smaller sizes. However, estimates derived from large grids reduce profile precision. A finer resolution grid and larger calibration sample (Rich \& Shively, 2004) can accommodate performance while producing a more refined estimate. A possible strategy for increasing the sample sizes was introduced in a study by Leitner and Kent (2009), which demonstrated how larger calibration samples could be obtained by including multi-offence crime series. Ideally, this solution should be implemented in future research.

\section{Conclusion}

This study set out to measure the theoretical and operational efficacy of incorporating land cover within a Bayesian formulated JTC estimation model. It represents an extension of previous research in which Kent and Leitner (2009) examined the effectiveness of filtering a JTC estimate using land cover characteristics attributed to known offenders. By successfully incorporating these land cover probabilities within a Bayesian framework, this study found that land cover enhancement techniques significantly improved profile probability estimates and lowered the search costs used to predict the location a serial offender's anchor point. In doing so, these findings support the premise that landscape characteristics can be used to exploit the relationship between an offender's anchor point and his/her perceptions of criminal opportunity and target attractiveness.

These results demonstrate that the integration of an offender's land cover type within existing geographic profiling routines can significantly improve a model's ability to expose the area containing an offender's anchor point, and thus provide law enforcement professionals with a method for prioritizing search strategies. We note that it is possible for our approach to produce inaccurate profiles, as would any method that has been applied to an intentionally deceptive offender (e.g., Washington, D.C., area serial snipers of 2002: Muhammad and Malvo). Moreover, because the profiles generated in this study were limited to offender anchor points confined to four land cover types, a comprehensive assessment of the land cover approach has yet to be conducted. Future research should assess this technique in diverse environments that are characterized by heterogeneous land cover classes. Finally, some may criticize the Bayesian approach as having a limited contribution to real-world investigations. While this technique may be inappropriate for suspect prioritization, it is well suited for developing areal search strategies. These critiques notwithstanding, the land cover Bayesian model represents a robust approach for modeling offender anchor points across diverse physical and cultural environments. The value of this or any Bayesian approach lies in its ability to incorporate multiple, independent explanatory variables within a geographic profile, thus further refining the routine's ability to locate an offender's anchor point. As research proceeds, Bayesian formulated models are likely to become the new standard by which geographic profiles are derived. Successful implementations of these techniques will ensure the continued contribution of geographic profiling to criminological theory and broaden its utilization as an investigative tool for suppressing serial crime. 


\section{Baltimore, Maryland, Study Area}

Journey-to-Crime Estimation

Larceny Serial Crime

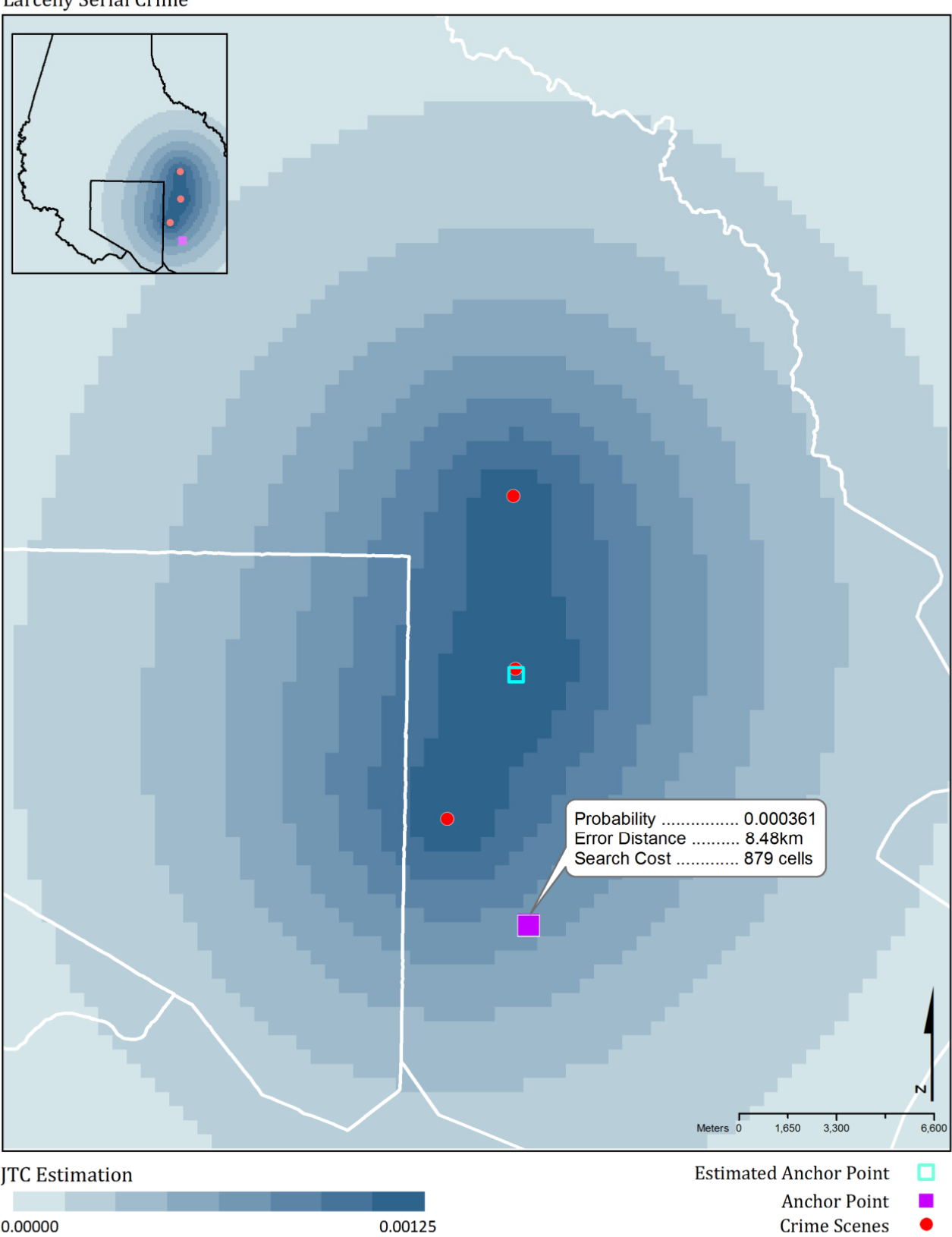

Maryland

Figure 3. Geographic profile generated using the JTC estimation model 
Baltimore, Maryland, Study Area

Filtered Journey-to-Crime Estimation

Larceny Serial Crime

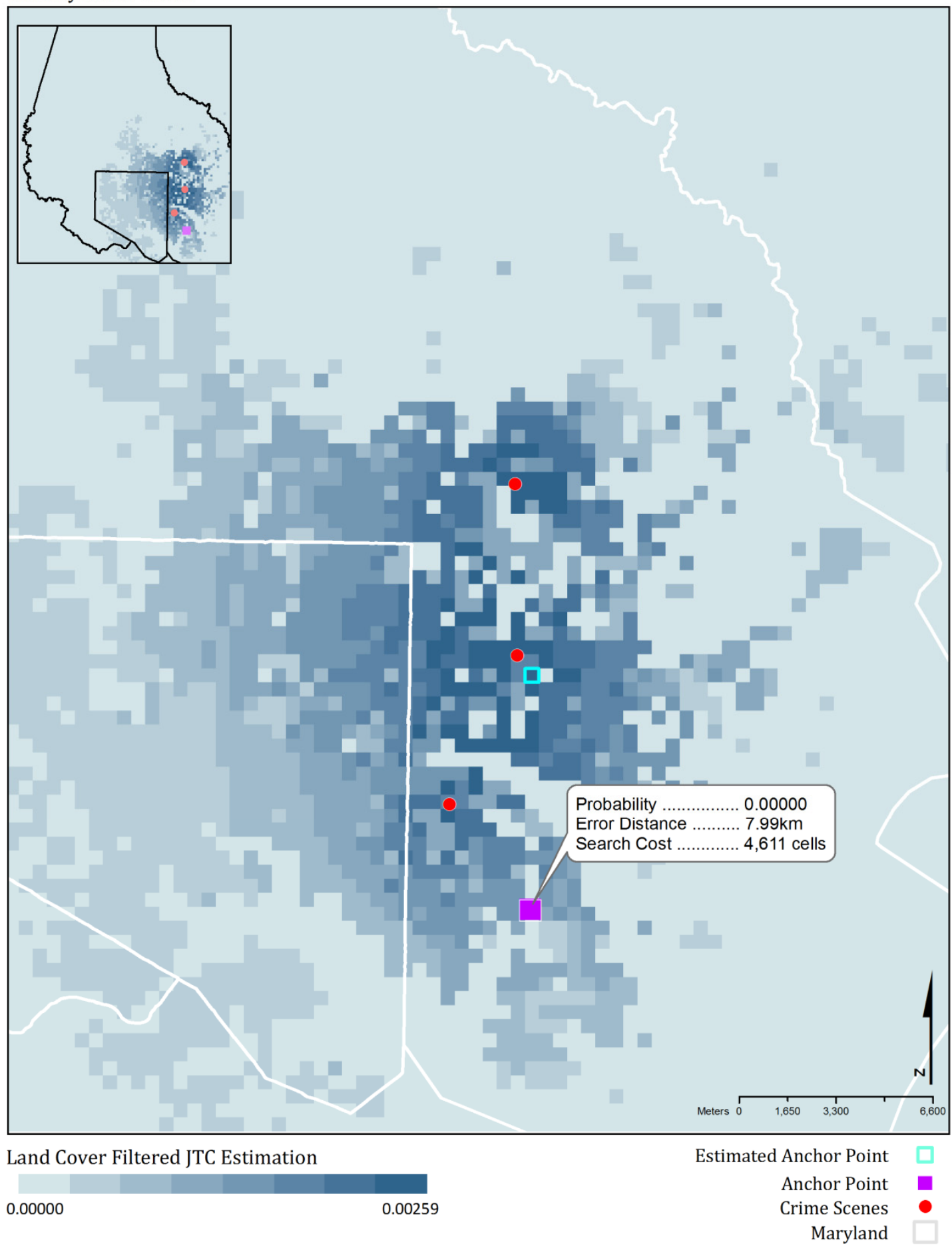

Figure 4. Geographic profile generated using the Filtered JTC estimation model 


\section{Baltimore, Maryland, Study Area}

Land Cover Enhanced Bayesian Product Estimation

Larceny Serial Crime

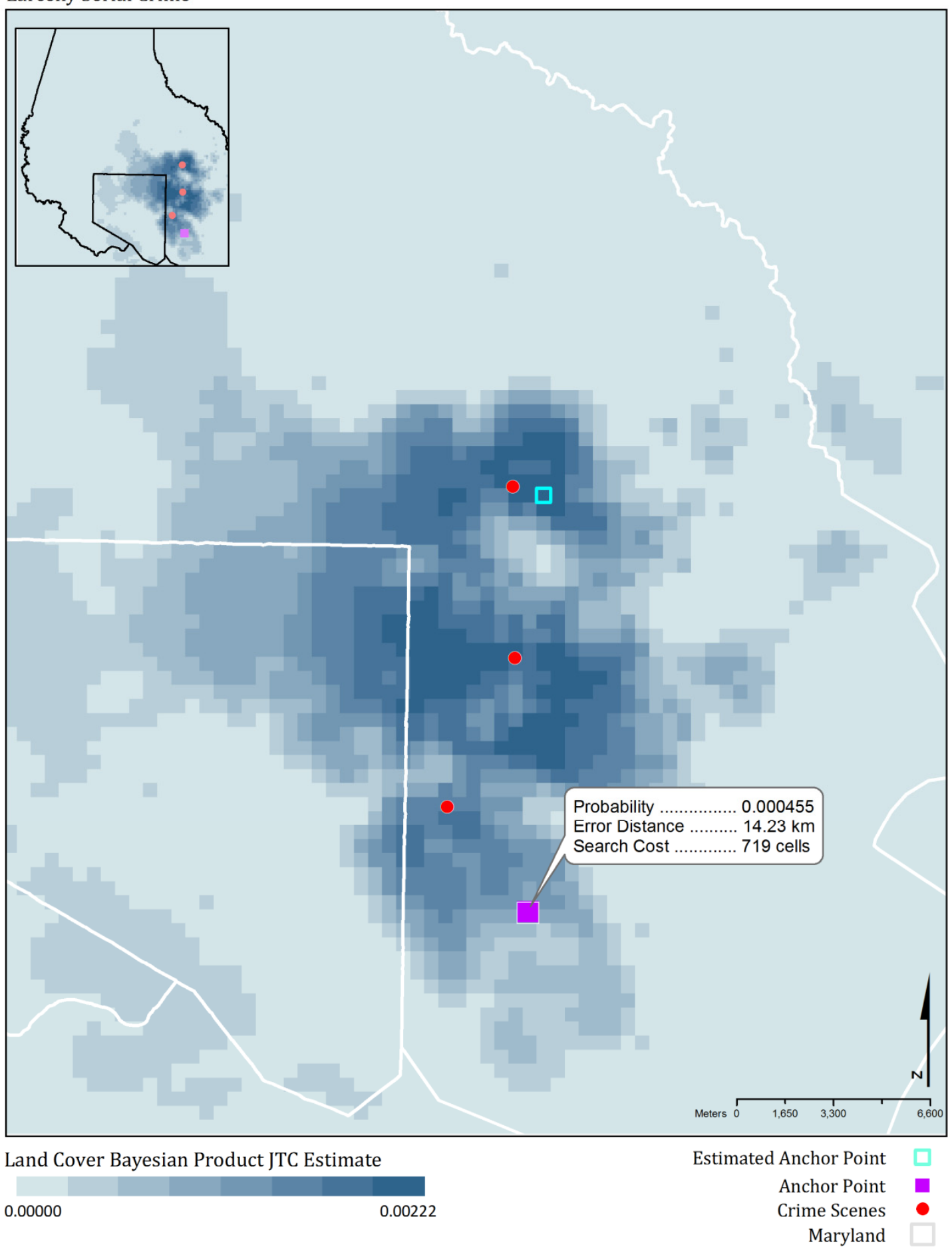

Figure 5. Geographic profile generated using the Land Cover Bayesian Product model 
Baltimore, Maryland, Study Area

Land Cover Enhanced Bayesian Posterior Estimation

Larceny Serial Crime

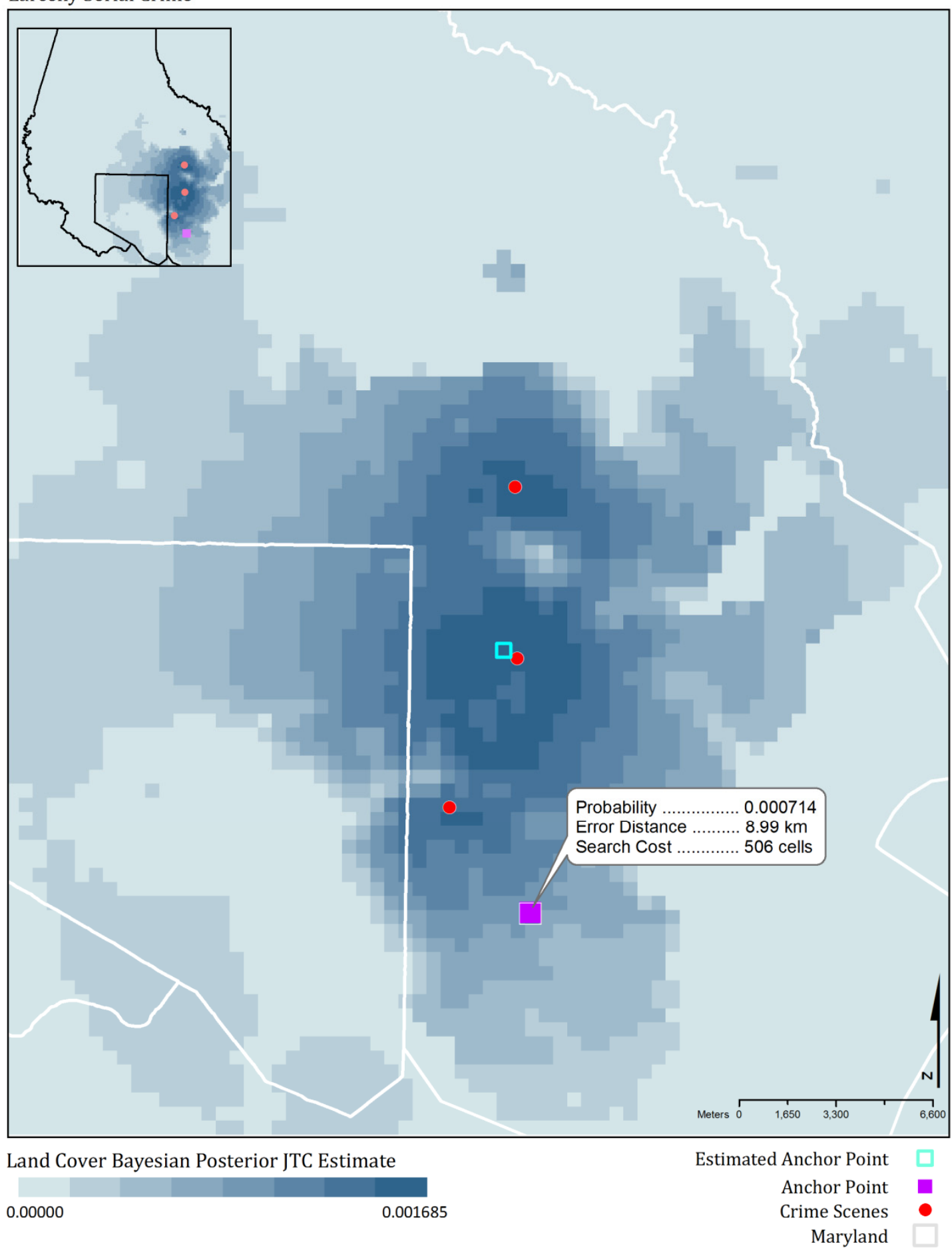

Figure 6. Geographic profile generated using the Land Cover Bayesian Posterior model 


\section{References}

Bernasco, W., \& Block, R. (2009). Where Offenders Chose to Attack: A Discrete Choice Model of Robberies in Chicago. Criminology, 47(1), 93-130. http://dx.doi.org/10.1111/j.1745-9125.2009.00140.x

Block, R., \& Bernasco, W. (2009). Finding a serial burglar's home using distance decay and conditional origin-destination patterns: a test of empirical Bayes journey-to-crime estimation in the Hague. Journal of Investigative Psychology and Offender Profiling. Special Issue: Bayesian Journey to Crime Modelling, 6(3), 187-211. http://dx.doi.org/10.1002/jip.108

Brantingham, P., \& Brantingham, P. (Eds.). (1981). Environmental Criminology. Beverly Hills, CA: Sage.

Canter, D., \& Hammond, L. (2006). A Comparison of the Efficacy of Different Decay Functions in Geographical Profiling for a Sample of US Serial Killers. Journal of Investigative Psychology and Offender Profiling, 3(2), 91-103. http://dx.doi.org/10.1002/jip.45

Canter, D., \& Larkin, P. (1993). The Environmental Range of Serial Rapists. Journal of Environmental Psychology, 13, 63-71. http://dx.doi.org/10.1016/S0272-4944(05)80215-4

Canter, D., Coffey, T., Huntley, M., \& Missen, C. (2000). Predicting Serial Killers' Home Base Using a Decision Support System. Journal of Quantitative Criminology, 16(4), 457-478. http://dx.doi.org/10.1023/A:1007551316253

Capone, D. L., \& Nichols, W. W. (1975). Crime and Distance: an Analysis of Offender Behavior in Space. Proceedings, Association of American Geographers, 7, 45-49.

Capone, D. L., \& Nichols, W. W. (1976). Urban Structure and Criminal Mobility. American Behavioral Scientist, 20(2), 199-213. http://dx.doi.org/10.1177/000276427602000203

Cohen, L. E., \& Felson, M. (1979). Social Change and Crime Rate Trends: A Routine Activity Approach. American Sociological Review, 44, 588-608. http://dx.doi.org/10.2307/2094589

Cornish, D. B., \& Clarke, R. V. (1986). Introduction. In D. B. Cornish \& R. V. Clarke, The Reasoning Criminal: Rational Choice Perspectives on Offending (pp. 13-45). New York: Springer-Verlag.

Feise, R. (2002). Do Multiple Outcome Measure Require P-Value Adjustment. BMC Medical Research Methodology, 2(8). http://dx.doi.org/10.1186/1471-2288-2-8

Felson, M., \& Clarke, R. V. (1998). Opportunity Makes the Thief - Practical theory for crime prevention. Research, Development and Statistics Directorate, Policing and Reducing Crime Unit. London: Home Office.

Kent, J., \& Leitner, M. (2009). Utilizing Land Cover Characteristics to Enhance Journey-to-Crime Estimation Models. Crime Mapping: A Journal of Research and Practice, 1(1), 33-54.

Kocsis, R. N., \& Irwin, H. J. (1997). An analysis of spatial patterns in serial rape, arson, and burglary: The utility of the circle theory of environmental range for psychological profiling. Psychiatry, Psychology and Law, 4(2), 195-206. http://dx.doi.org/10.1080/13218719709524910

LeBeau, J. L. (1987). Methods and Measures of Centrography and the Spatial Dynamics of Rape. Journal of Quantitative Criminology, 3(2), 125-141. http://dx.doi.org/10.1007/BF01064212

Leitner, M., \& Kent, J. (2009). Bayesian journey-to-crime modelling of single and multiple crime-type series in Baltimore County, MD. In N. Levine, \& R. Block, Bayesian Journey-to-Crime Estimation. Special issue of Journal of Investigative Psychology \& Offender Profiling, 6(3), 213-236. http://dx.doi.org/10.1002/jip.109

Leitner, M., Kent, J., Oldfield, I., \& Swoope, E. (2007). Geoforensic Analysis Revisited - The Application of Newton's Geographic Profiling Method to Serial Burglaries in London, UK. Elizabeth, 8(4), 359-370. $\mathrm{http}: / / \mathrm{dx}$. doi.org/10.1080/15614260701615060

Levine, N. (2005, May 08). Response to Kim Rossmo Critique of the GP Evaluation Methodology - May 08, 2005 .

Retrieved

from

http://www.nedlevine.com/Response\%20to\%20Kim\%20Rossmo\%20Critique\%20of\%20the\%20GP\%20Eva luation\%20Methodology.May\%208\%202005.doc

Levine, N. (2007). CrimeStat: A Spatial Statistics Program for the Analysis of Crime Incident Locations (v 3.1). Houston, TX and Washington, DC: Ned Levine \& Associates and the National Institute of Justice.

Levine, N. (2009). Introduction to the special issue on Bayesian journey-to-crime modelling. Journal of Investigative Psychology and Offender Profiling, 6(3), 167-185. http://dx.doi.org/10.1002/jip.107 
Lottier, S. (1938). Distribution of Criminal Offenses in Sectional Regions. Journal of Criminal Law and Criminology, 29(3), 329-344. Retrieved from http://www.jstor.org/stable/1137820

Newton, M. B., \& Swoope, E. A. (1987). Geoforensic Analysis of Localized Serial Murder: The Hillside Stranglers Located. 39th Annual Meeting of the American Academy of Forensic Sciences. San Diego, CA.

NOAA. (1996). Land Cover Analysis - C-CAP Classification Scheme. Retrieved from: http://www.csc.noaa.gov/crs/lca/tech_cls.html

O'Leary, M. (2009). The mathematics of geographic profiling. (N. Levine \& R. Block, Eds.) Journal of Investigative Psychology and Offender Profiling. Special Issue: Bayesian Journey to Crime Modelling, 6(3), 253-265. http://dx.doi.org/10.1002/jip.111

Paulsen, D. (2006a). Human versus machine: A comparison of the accuracy of geographic profiling methods. Journal of Investigative Pscyhology and Offender Profiling, 3(2), 77-89. http://dx.doi.org/10.1002/jip.46

Paulsen, D. (2006b). Connecting the Dots: Assessing the Accuracy of Geographic Profiling Software. Policing: An International Journal of Police Strategies \& Management, 29(2), 306-334. http://dx.doi.org/10.1108/13639510610667682

Rengert, G. F., Piquero, A. R., \& Jones, P. R. (1999). Distance decay reexamined. Criminology, 37(2), 427-446. http://dx.doi.org/10.1111/j.1745-9125.1999.tb00492.x

Rhodes, W. M., \& Conly, C. (1981). Crime and Mobility: An Empirical Study. In P. J. Brantingham \& P. L. Brantingham (Eds.), Environmental Criminology. Beverly Hills, CA: Sage.

Rich, T., \& Shively, M. (2004). A Methodology for Evaluating Geographic Profiling Software. Abt Associates, Inc. Cambridge, MA: National Institute of Justice.

Rossmo, D. K. (2000). Geographic Profiling. Boca Raton, Florida, USA: CRC Press.

Rossmo, D. K. (2005, March 9). An Evaluation of NIJ's Evaluation Methodology for Geographic Profiling Software. Retrieved from http://txstate.edu/gii/documents/Response\%20to\%20NIJ\%20GP\%20Evaluation\%20Methodology.doc

Rothman, K. J. (1990). No adjustments are needed for multiple comparisons. Epidemiology, 1, 43-46. Retrieved from http://www.jstor.org/stable/20065622

Smith, W., Bond, J. W., \& Townsley, M. (2009). Determining How Journeys-to-Crime Vary: Measuring Interand Intra-Offender Crime Trip Distributions. In D. Weisburd, W. Bernasco \& G. J. Bruinsma, Putting Crime in its Place: Units of Analysis in Geographic Criminology (pp. 217-263). New York: Springer New York.

Snook, B., Canter, D., \& Bennell, C. (2002). Predicting the home location of serial offenders: a preliminary comparison of the accuracy of human judges with a geographic profiling system. Behavioral Sciences \& the Law, 20(1-2), 109-119. http://dx.doi.org/10.1002/bsl.474

Snook, B., Zito, M., Bennell, C., \& Taylor, P. J. (2005). On the complexity and accuracy of geographic profiling strategies. Journal of Quantitative Criminology, 21(1), 1-26. http://dx.doi.org/10.1007/s10940-004-1785-4

Taylor, P. J., Bennell, C., \& Snook, B. (2009). The bounds of cognitive heuristic performance on the geographic profiling task. Applied Cognitive Psychology, 23(3), 410-430. http://dx.doi.org/10.1002/acp.1469

Turner, S. (1969). Delinquency and distance. In M. E. Wolfgang \& T. Sellin, Delinquency: Selected Studies. New York: John Wiley and Sons, Ltd.

Van Koppen, P. J., \& de Keijser, J. W. (1997). Desisting Distance Decay: On the Aggregation of Individual Crime Trips. Criminology, 35(3), 505-515. http://dx.doi.org/10.1111/j.1745-9125.1997.tb01227.x 